\title{
Barriers to the composition and implementation of advance directives in oncology: a literature review
}

\author{
Pedro Grachinski Buiar ${ }^{1 a}$ (iD) and José Roberto Goldim² \\ ${ }^{1}$ Medical Oncology Department, Hospital de Clínicas de Porto Alegre (HCPA), Porto Alegre, RS 90035-007, Brazil \\ ${ }^{2}$ Bioethics Division, Hospital de Clínicas de Porto Alegre (HCPA), Porto Alegre, RS 90035-007, Brazil \\ ahttp://orcid.org/0000-0001-5144-1197 \\ bhttp://orcid.org/0000-0003-2127-6594
}

\begin{abstract}
The advance directive (AD) is an important resource in oncology and all areas of medicine directly involved in the care of palliative patients. It provides people with the right to have their living wills honoured when they cannot respond by themselves. Despite their importance, $A D s$ are still underused in most countries due to multiple factors. The objective of this review is to better categorise the barriers and difficulties that could impair the composition and implementation of ADs, allowing direct efforts against these obstacles. After the literature review, we believe that there would be five steps in the trajectory of an $A D$ (discussion, composition, registration, access and implementation) and that all those steps can be affected by factors involving the health systems and professionals, the patient themselves and relatives or caregivers.
\end{abstract}

Keywords: advance directive, cancer, neoplasm, factors, palliative, living wills

\section{Introduction}

Advances in cancer treatment have increased the number of patients with prolonged survival [1]. One major threat in modern oncology is the excessive focus on treatment response rates and the tendency to neglect research and studies about the care of dying people [2]. The concept of patient-centred care is built on patient preferences and beliefs [3]. And those should be readily available in the form of advance directives (ADs), one of the products derived from the Advance Care Planning process which should be started at the moment of an incurable diagnosis and maintained throughout the palliative trajectory (Figure 1) of the cancer patient [4]. An AD is commonly manifested by two documents, the Living will (that is directly related to the patient-specific preferences, regarding the medical care they want to receive, including preferences like place of death, life-sustaining treatments and any other points of treatment or care that are important to the person) and the Power of Attorney (a document that enables another person to decide on the name and to handle questions that an incapable person leaves unresolved).
Correspondence to: Pedro Grachinski Buiar Email: pgbuiar@gmail.com

ecancer 2019, 13:974

https://doi.org/10.3332/ecancer.2019.974

Published: $12 / 11 / 2019$

Received: 09/07/2019

Publication costs for this article were supported by ecancer (UK Charity number 1176307).

Copyright: $(\subset$ the authors; licensee ecancermedicalscience. This is an Open Access article distributed under the terms of the Creative Commons Attribution License (http:// creativecommons.org/licenses/by/3.0), which permits unrestricted use, distribution, and reproduction in any medium, provided the original work is properly cited. 


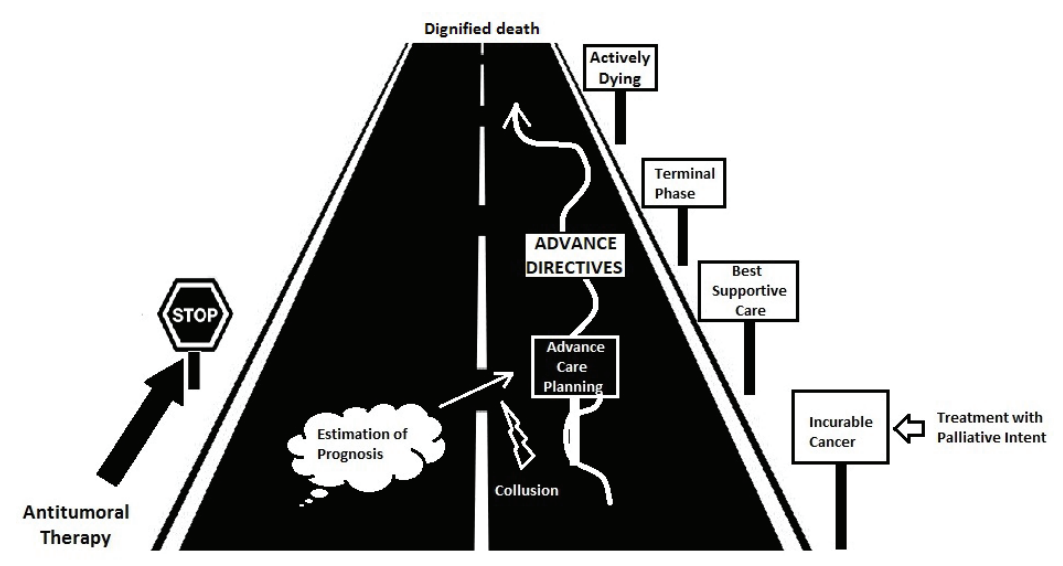

THE PALLIATIVE ROAD

Figure 1. 'The palliative road' illustrates the trajectory of the patient in palliative treatment since the diagnosis of the incurable disease until the death event, going through all the steps marked in the evolutionary history of the disease. Ideally, ADs should arise from the beginning and accompany the patient through the entire trajectory contributing to a good death in the end.

ADs contribute to the attenuation of suffering (of patient and family) and anxiety, to the augmentation of autonomy, psychological relief and patient satisfaction [5]. Health systems are benefited too, with a reduction in unnecessary costs [6-9].

Despite the benefits referred to above, the implementation rates of ADs vary widely in the literature. A recent systematic review, analysing 795,909 people in the United States, indicated a stable percentage of around $36.7 \%$ of adults having ADs, and $29.3 \%$ were characterized as living wills [10]. Restricting the analysis to patients with cancer, this number reaches a rate of nearly $70 \%$ [11].

ADs are derived from the Advance Care Plan (ACP), which is not a concrete object but a process developed over time and constructed through shared decision-making. This process could also be impaired by a lot of factors such as lack of experience by physicians, absence of adequate protocols, difficulty in estimating prognosis and providing information, difficulty in talking about death and making decisions about future scenarios, slow decision-making capacity by patients, low level of concordance between the patient's wishes and family opinion and many other factors [12-15].

The main objective of this study is to review the major obstacles making it difficult for palliative patients to exert full autonomy, achieving a 'good death' by having their beliefs and wishes respected.

\section{Methods}

We performed a literature review using the PubMed database looking to respond to the question 'What are the barriers and difficulties preventing the advance directives being successful?'. The descriptors used were 'Advance Care Planning', 'Advance Directives', 'Cancer', 'Oncologic ${ }^{* \prime}$ and 'Palliative'. Articles published in the past 40 years were considered, obtaining a total of 1,227 articles. After excluding articles of editorials, paediatric cancer patients, noncancerous patients with dementia and articles not published in the English language, we reviewed 121 articles and selected 81 for this review paper composition. The final search was performed in June 2019. 


\section{Results}

\section{Health system-related factors}

Early discussions about advanced care should be initiated when patients are in outpatient/office-based care. In a stable clinical period, with adequate time and place for reflection, people have the most appropriate conditions for discussion and review of directives. It must be clarified to the patient and family that ACP and ADs are not a 'one-time event' [16]. It can be reviewed and replaced at each visit or whenever a new event changes the patient condition or prognosis. A cohort study by Mack and colleagues demonstrated an inverse association between endof-life (EoL) discussions before the last 30 days of life and the application of aggressive measures [17]. The ability to prognosticate correctly is involved in the aggressiveness of EoL care in patients with metastatic cancer receiving palliative therapy. Patients receiving an incorrect life prediction are more likely to suffer aggressive EoL care (OR 2.55; 95\% Cl, 1.09-5.99; $p=0.03)$ [18].

It is not uncommon to see health professionals believing that EoL discussions will lead patients to higher levels of stress and discomfort. Evidence shows that up to $98 \%$ of patients with less than 6 months of life expectancy want realistic information from their physicians, but $91 \%$ of these patients report that the physician is uncomfortable or nervous with this type of conversation [19]. In another study that evaluated patients desiring to be informed about prognosis, only half of them were informed about life expectancy [20]. Finally, it is also important to bear in mind that the majority of patients do not complain about additional depression/anxiety after discussions about prognosis. Actually, the lack of prognostic information is considered a real complaint regarding EoL care [9, 21, 22]. This fear of addressing bad news and discussing ACPs and ADs on the part of doctors and health professionals should be mitigated in the light of the current evidence.

If we look at physician behaviour when caring for cancer patients, we see that only $18 \%$ of doctors talk about do-not-resuscitate (DNR) status promptly versus $26 \%$ that wait until there is no more antitumour active treatment available. Considering the conversation about palliative care enrolment, the percentage of doctors that postpone this discussion until there are no more available treatments rises to $49 \%$. In the multivariable analyses, one factor associated with earlier talks about hospices was the office-based practice $(p=0.007)$. Another interesting aspect is that the oncologist is the specialist that discusses prognosis more frequently, but the non-cancer specialist is responsible for the majority of early discussions about DNR code, hospice enrolment and site of death $(p<0.001)$ [23]. Although the general population asserts that the diagnosis of advanced and incurable cancer is reason enough to trigger this discussion between family and physician, most health professionals say they do not initiate EoL discussions with patients who are feeling well but wait until they become symptomatic or there are no more available antitumour treatments. This fact may explain why 75\% of patients want their physicians to start discussions about EoL and ACPs but only $5 \%$ of doctors start this task in some retrospective series [24, 25]. When we look at the oncologists' performance, half of them contribute to their patient's ADs [26].

A personal history of palliative care consultation elevates the odds of advance care planning documentation (OR 6.79, $p \leq 0.001)[27]$ and the different global availability of palliative care referral could be a reason for disparities in the literature [28].

Even after they have been created and registered, ADs might be not followed. A study published by Biola et al [29] found that 89.1\% of the relatives of terminally ill patients reported a decision on resuscitation, $82.1 \%$ on artificial enteral nutrition, $64.3 \%$ on the administration of antibiotics and $83.7 \%$ on transfer to hospitals. Paradoxically, the directive was not followed by the medical team in $71.4 \%$ of the resuscitations, $14.3 \%$ of the enteric tubes, $19.2 \%$ of antibiotics and $29.9 \%$ of the hospital transfers. One possible cause for this might be a loss of information during the transition between different sites and teams of medical assistance, for example, from home to emergency rooms. The emergency departments are visited by a lot of cancer patients, and patients in terminal conditions routinely receive some type of invasive lifesustaining measure [30,31]. Emergency departments are not the best place for difficult conversations and complex decision-making regarding discontinuation/abstention of therapies [32]. For this reason, ADs should be readily available and documented in some type of portable device [33]. An instrument developed trying to mitigate this problem is called Physician Orders for Life-Sustaining Treatment (POLST). POLST is an EoL care transition programme that focuses on patient-centred goals and that informs shared decision-making directives. It provides a mechanism to communicate the desires of severely ill patients regarding medical treatments to be instituted or avoided in transition between 
health institutions and health teams. The objective is to standardise and make the living wills prevail over any opinion, conduct or focus that may vary among different health institutions or professionals across the patient trajectory [34]. Despite this, mechanisms relying on physical documents are susceptible to losses and problems of visualisation/interpretation. One way to overcome this barrier is the use of a shared electronic health system to register and deliver medical information about patient decisions in EoL. But an electronic health registry needs to be shared between health facilities, to be organised centrally and also needs to provide training and stimulus for the documentation of goals of care [35].

Recently, a randomised clinical trial concluded that a communication quality-improvement intervention (that included clinician and patient tools, clinician training and some practical systems changes) could raise the rates of documented discussions about preferences, goals and prognosis (96\% versus $79 \%$ ) and found that those discussions occurred earlier when compared with the control group (median of 2.4 months; $p<0.001$ ). However, despite the positive effect regarding conversations, the effective documentation of EoL plans did not reach a statically significant difference [36]. This could be explained by the influence of multiples factors involved with the ADs and the ACP.

Finally, even apparently simple and unexpected details such as a correct palliative International Classification of Diseases 10th edition code and a primary care connection could prevent unnecessary emergency visits [37].

\section{Patient-related factors}

Demographic data associated with the higher rates of ADs registration include being Caucasian, high educational level, high economy category, residents of nursing homes and subjects with a neoplasm diagnosis [38]. The decisional patterns regarding patient preferences vary around the globe, from active to passive models, like those encountered in Singapore, South Africa and Brazil [39].

One important modifiable factor involved in the composition of ADs is the lack of knowledge/poor understanding regarding illness, which may be attributed to patient-related lack of interest or to physician's omission [40]. A study involving patients with stage IV lung and colorectal disease who received palliative chemotherapy showed that only $33 \%$ of them recognised the chemotherapy as not curative. This group of patients was more likely to enrol in hospice care and also to receive less aggressive measures (OR 1.97, 95\% $\mathrm{Cl}=1.26-2.66)$ [41].

Another main reason patients fail to complete their directives is the difficulty in anticipating their wills based on scenario projections and specifying preferences or limitations for life-sustaining therapies, a fact that can be attenuated by the presence and help from a medical professional during the discussion of directives and document composition [5, 24, 42]. Ideally, this professional should be the long-term assistant physician.

One way to overcome these barriers related to scenario projection is the use of complementary instruction mechanisms like educational videos, something that gives more power to the patient in the decision process [43].

Discussions about EoL are one of the most difficult conversations in all medicine. Eighty-four percent of patients would like to discuss treatment symptoms and toxic effects at the time of diagnosis of metastatic disease, and $59 \%$ of them would like to discuss life expectancy at the same moment [44]. At some point, the patient needs to know their prognosis since those who do not know usually tend to prefer more aggressive treatments [45]. Nowadays, it is acceptable to have some uncertainty around prognostication with the addition of new treatments and clinical trials enrolment. We must bear in mind that these new treatment results were not included in the majority of classical prognostic models and nomograms [46].

When we look at metastatic subjects who have already decided, we see that only $39.5 \%$ have a preference for non-resuscitation but only half of those had their orders for non-resuscitation documented. It is imperative to think about the reasons for this number [47].

A study evaluating 2,538 terminal cancer subjects admitted to the Palliative Care Unit of a Cancer Centre with a clear medical indication of non-resuscitation found a $4 \%$ rate of non-resuscitation order refusal by those patients. The factors associated with this behaviour are poor analgesic control $(p=0.0005)$, presence of nausea $(p=0.05)$ and dyspnoea $(p=0.002)$. After multivariate analysis, the association is with moderate to severe pain (OR 3.19, $p=0.002$ ) and the absence of registered living wills (OR 2.94, $p=0.001$ ) [48]. This data illustrates the importance of the management of factors at the patient level, like adequate symptoms control and higher quality of life provision.

Another problem in composing a directive may be the lack of time due to the rapid evolution of the disease accompanied by cognitive impairment and worsening of the general health condition. A large retrospective study with more than 200,000 cases show that the median 
interval (in days) between the DNR order signature and the patient death was 0 days, i.e., on the same day, the patient had died. On subgroup analysis, subjects in the outpatient scenario had a median interval of 30 days between DNR status signature and death [49].

This may illustrate the tendency of the decision-making process to occur closer to death. We know that cancer patients have an abrupt decline of their functional capacity in their last 3 months of life and that the cognitive decision-making capacity in terminal patients tends to be more limited [50]. The ability to express a choice is preserved, but the understanding, processing and reasoning capacity seem to be impaired [51]. Despite guidelines recommending ADs discussions occur as soon as possible, decisions like DNR are still occurring late or very close to the death event [47, 52-55].

The amount of time dispensed to ACP and EoL discussions in an office-based consult are important. Approximately $90 \%$ of patients exposed to some forms of ADs have not completed these documents and say they still needed additional information and time to take some of the decisions [56]. As a result, this task frequently ends in the hands of a relative/caregiver.

\section{Caregiver and relative-related factors}

The family plays a central role in the support of the patient near to the EoL and in the decision-making process [57, 58]. Despite being recognised by the health team as representatives of the patients, it is common that those relatives have not been formally designated by the patients themselves as attorneys. And those people, given the burden of responsibility and feelings like guilt or regret, may choose to maximise the patient's life, no matter how iatrogenic it may be.

A 12-year prospective study analysing changes in the prevalence rate of the ACP followed patients from 2000 to 2012 and found that despite a significant increase in the Durable Power of Attorney rate (52\%-74\%), the rates of living wills (40\%) and discussions with patients about EoL questions (60\%) did not change [59]. Clinicians need to bear in mind that the results from a discussion about EoL with relatives may be too distant from the results of the same discussion with the patient himself.

In paternalistic cultures, where the family assumes the responsibility of decision-making regarding the patient's EoL, we can witness the phenomenon called 'collusion'-behaviour characterised by hiding the truth from patients with the tendency to make decisions without including them in the process and discussing with third parties. Some studies indicate that about $95.2 \%$ of registered ADs were actually defined by the family members in charge, and not by the patient themselves [11]. Other data showed up to $87 \%$ of prognoses are first revealed to a family member of a cancer patient [19]. One potential detrimental effect resulting from decisions taken by family members is the possible divergence of opinions between the family member and the patient. Especially when there was insufficient time for that family member to reflect and think about the patient's preferences in life [60]. It is very important to reinforce that the directives should be ideally created by the patient themselves, as personal autonomy is one of the key ethical principles of modern medicine.

One way to alleviate the potential suffering and pressure of family members responsible for EoL decisions would be to extend the interval between the beginning of these discussions and the date of the patient's death [61,62]. There are also some data that show that when requested early and under adequate conditions, the involvement of the relative is associated with increased patient satisfaction and reduced levels of depression and anguish [63]. The simple fact of being nominated as a legal representative previously to the outcomes of the ill patient could also alleviate the psychological charge in the family members [64].

One independent factor related to caregivers is their educational level. A study suggests that the desire for aggressive measures and life-sustaining treatments for the patient tends to be inversely proportional to the cognitive level of their caregivers [65].

We cannot ignore that even when finalised, ADs may fail to achieve their goals when the patient and family members do not understand how they will be used or their goal. It is estimated that $28 \%-30 \%$ of patients did not discuss their AD with family members for undefined reasons. The same data also revealed that up to $91 \%$ of these patients did not discuss their ADs with the attending physicians $[66,67]$. Every health professional should be alert and actively question the patient about living wills.

Finally, we should keep in mind the implications for caregivers and relatives who must take the decision in the name of the patient. A study with patients who had died in intensive care units revealed that the rate of post-traumatic symptoms in the relatives who took direct decisions for the patient was $82 \%$ compared to $60 \%$ in the relatives whose decision was not required [68]. 


\section{Low quality of evidence regarding $A D$ and life-sustaining measures}

There is a lack of randomised controlled studies to assess the benefit of life-sustaining measures in the palliative scenario. A Korean study evaluating decisions of terminal patients classified the life-sustaining treatments into two types: General and special. General measures were considered to be enteral feeding tubes, oxygen therapy and laxatives and special treatments were considered to be cardiopulmonary resuscitation, mechanical ventilation, dialysis, blood components transfusions, chemotherapy and wide-spectrum antibiotics [11].

The concept of 'futility of a treatment' is defined quantitatively, by the probability of therapeutic success, and qualitatively, by the value conceived in terms of quality of life [32]. A futile treatment is characterised by the absence of benefits, or by the disproportion between benefits and associated risks. Health Practitioners should always keep in mind that the value of small gains in overall survival is extremely controversial. Seven days could mean everything for a patient that has some degree of life and social interaction or could mean nothing to a patient with no interaction, in suffering or bedbound. An appropriate ACP constructed through a shared decision-making process with the composition of an AD may be the most appropriate tool to guide difficult health decisions.

Artificial nutrition in oncology is prescribed mostly to maintain nutrition support in patients unable to eat during the active antitumour treatment, either due to cancer- or treatment-related effects. Artificial nutrition in patients with limited prognosis does not seem to change outcomes in the course of advanced disease [69]. Parenteral hydration also seems to have limited value to prolong survival, in this case with a randomised placebo-controlled trial demonstrating no difference in median survival, although this trial had not obtained sufficient statistical power ( $p=0.83$ ) [70]. Regarding cardiopulmonary resuscitation (CPR) in cancer patients, a meta-analysis of 42 studies comprising 1,707 cancer patients submitted to an in-hospital CPR concluded that the overall survival rate was $5.6 \%$ for metastatic patients and $9.5 \%$ for patients with localised disease [71]. A large cohort study published after this meta-analysis compared the resuscitation outcomes of patients with and without advanced cancer. Cancer patients achieved a $7.4 \%$ rate of survival to discharge compared with $13.4 \%$ of matched subjects without cancer $(p<0.001)$ [72].

Blood components transfusion in terminally ill cancer patients is another question for debate. A Cochrane Review evaluating blood transfusions in cancer patients found no randomised clinical trials and concluded that $31 \%-70 \%$ of patients with advanced cancer showed some degree of improvement in breathlessness, fatigue and general well-being. This review also found that $35 \%$ of patients die within 2 weeks after the palliative transfusion [73]. A retrospective study analysed 309 dying patients with terminal cancer between 2010 and 2011 and compared the survival outcome of patients that received blood transfusion versus controls without transfusions. This study found that $90 \%$ of patients had anaemia during their last hospitalisation and $38.4 \%$ received red blood cells (RBC) transfusion. The median survival in the transfusion group was 15 days versus 8 days in the group with no RBC transfusion $(p<0.001)$ [74].

Unwanted and unnecessary hospitalisations are routine in the disease evolution of terminal cancer patients, and several studies demonstrated that the main reason for this type of hospital admission is for symptom control [75-79]. The main complications and causes of death in cancer patients are sepsis, respiratory obstruction, intestinal obstruction, spinal cord compression and thrombosis [80]. It is mandatory to distinguish symptoms of easy palliation from scenarios where symptomatic relief necessarily depends on the reversal of those severe cancer-related complications, requiring aggressive procedures [81]. The question that arises is the actual magnitude of benefit from those interventions and the patient's willingness to receive such interventions, with a potential risk for death without guarantee of symptomatic control, life prolongation or improvement in the quality of life.

\section{Conclusion}

The major goal of the advance care planning process and ADs is to give the patient the right to a dignified death at the end of their life. This review inferred that there are a lot of factors that could affect the ACP process and ADs in a positive or negative manner, in all their phases (discussion, composition, registration, access and implementation-Figure 2). 
We can divide those factors into non-modifiable and modifiable, and distribute them by steps, scenarios and people involved in the process of AD creation. Making an analogy with the 'Swiss cheese model' [82], we could say that the ACP and ADs must overcome a series of steps and multifactorial obstacles to be successful in their final objective (Figure 3). All medical specialists involved in the care of cancer patients with incurable conditions should pay attention to these factors and possible barriers, especially those potentially modifiable and directly influenced by our practice. An AD elaborated by the patient themselves, and that anticipates all the possible conflicts, is the best tool to make the right decision, and it is imperative to have in mind that after created, the AD should not be destroyed, forgotten or underused.

In the era of innovative and promising treatments, the medical practitioner should keep in mind that no matter how long the journey of life, the only certainty is the end. Some patients need aggressive treatments and others do not, some have opportunities to enter clinical trials and others do not and some have greater survival than others. Each palliative patient has a different trajectory. However, the common factor for all is the desire for a dignified death.

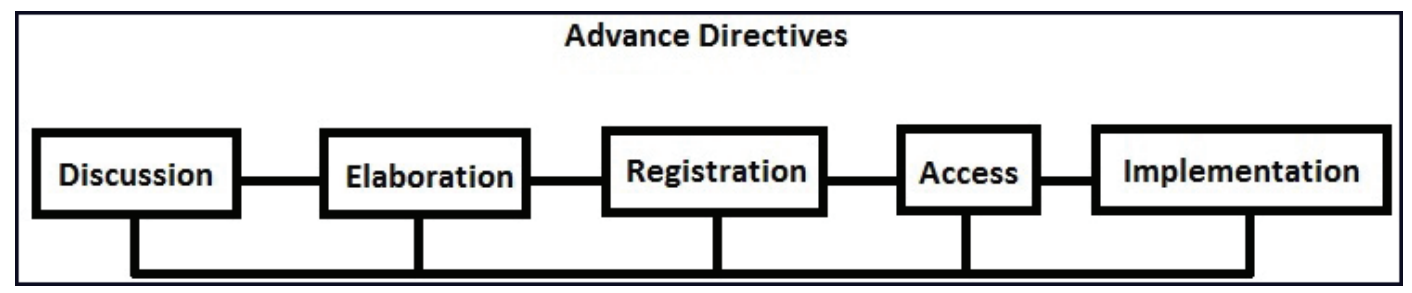

Figure 2. Five steps for a successfully implemented AD.

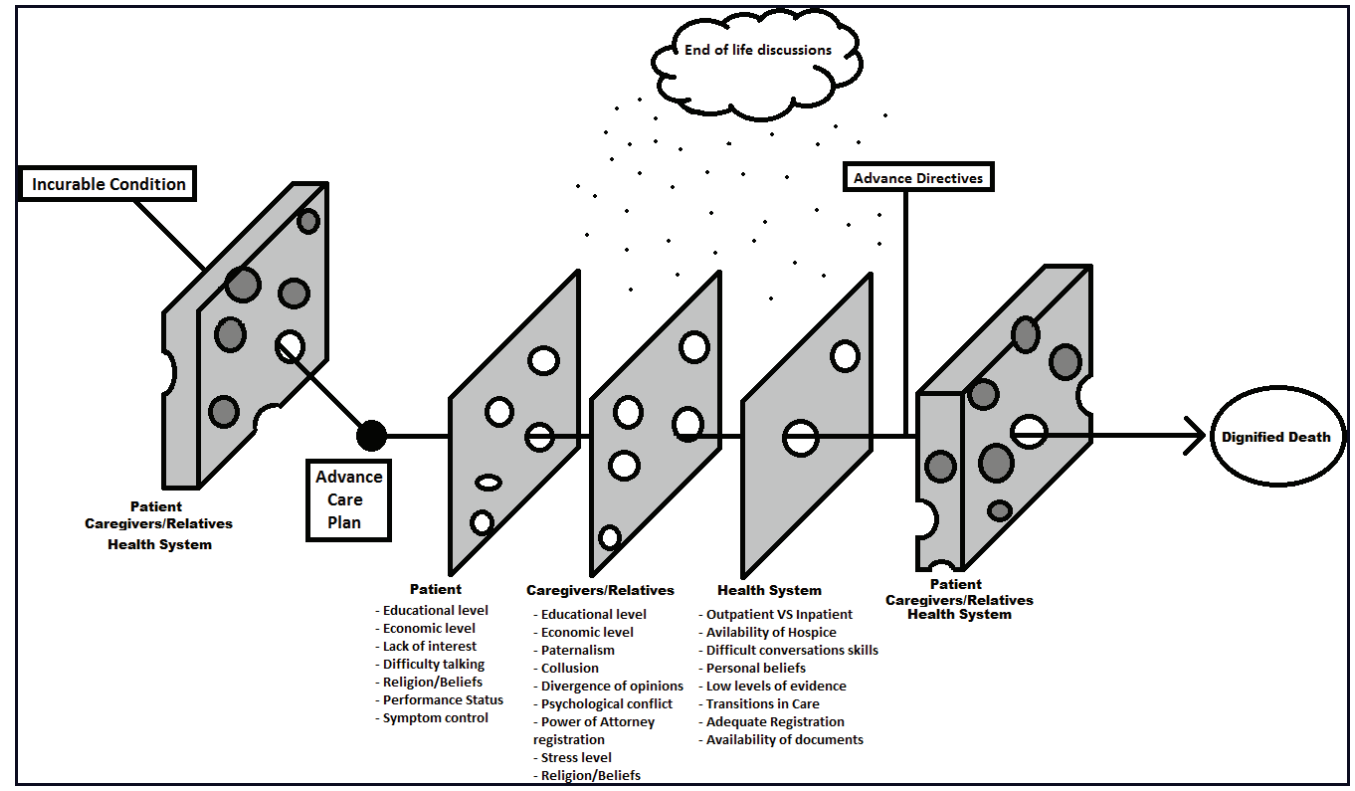

Figure 3. The multiple obstacles and barriers that ACP and ADs must pass through to guide the patient to their desired end.

\section{Conflicts of interest}

The authors declare that they have no conflicts of interest. 


\section{Funding}

All the authors declare no access to funding support.

\section{References}

1. Silbermann M, Arnaout M, and Daher M, et al., (2012) Palliative cancer care in Middle Eastern countries: accomplishments and challenges Ann Oncol 23 (suppl 3) 15-28 https://doi.org/10.1093/annonc/mds084 PMID: 22628412 PMCID: 3493144

2. Corner J (1997) Beyond survival rates and side effects: cancer nursing as therapy. The Robert Tiffany Lecture. $9^{\text {th }}$ International Conference on Cancer Nursing, Brighton, UK, August 1996 Cancer Nurs 20 3-11 https://doi.org/10.1097/00002820-199702000-00002 PMID: 9033145

3. Institute of Medicine (US) Committee on Quality of Health Care in America (2001) Crossing The Quality Chasm: A New Health System for the 21st Century (Washington DC: National Academies Press) p. 1192

4. Sudore RL, Lum HD, and You JJ, et al. (2017) Defining advance care planning for adults: a consensus definition from a multidisciplinary Delphi panel J Pain Symptom Manage 53 821-832.e1 https://doi.org/10.1016/j.jpainsymman.2016.12.331 PMID: 28062339 PMCID: 5728651

5. Pautex S, Herrmann FR, and Zulian GB (2008) Role of advance directives in palliative care units: a prospective study Palliat Med 22 835-841 https://doi.org/10.1177/0269216308094336 PMID: 18718993

6. Mahon MM (2011) An advance directive in two questions J Pain Symptom Manage 41 801-807 https://doi.org/10.1016/j.jpainsymman.2011.01.002 PMID: 21398084

7. Temel JS, Greer JA, and Muzikansky A, et al. (2010) Early palliative care for patients with metastatic non-small cell lung cancer N Engl J Med 363 733-742 https://doi.org/10.1056/NEJMoa1000678 PMID: 20818875

8. Schmidt TA, Zive D, and Fromme EK, et al. (2014) Physician orders for life-sustaining treatment (POLST): lessons learned from analysis of the Oregon POLST Registry Resuscitation 85 480-485 https://doi.org/10.1016/j.resuscitation.2013.11.027 PMID: 24407052

9. Mack JW and Smith TJ (2012) Reasons why physicians do not have discussions about poor prognosis, why it matters, and what can be improved J Clin Oncol 30 2715-2717 https://doi.org/10.1200/JCO.2012.42.4564 PMID: 22753911

10. Yadav KN, Gabler NB, and Cooney E, et al. (2017) Approximately one in three US adults completes any type of advance directive for end-of-life care Health Aff (Millwood) 36(7) 1244-1251 https://doi.org/10.1377/hlthaff.2017.0175

11. Kwon SH, Im SH, and Cho KW, et al. (2012) Most advance directives written by patients with advanced cancer or their proxies request only minimally invasive treatments during end-of-life care Am J Hosp Palliat Care 29(8) 622-626 https://doi. org/10.1177/1049909111435811 PMID: 22363040

12. Ditto PH and Hawkins NA (2005) Advance directives and cancer decision making near the end of life Health Psychol 24(Suppl 4), S63S70 https://doi.org/10.1037/0278-6133.24.4.S63 PMID: 16045421

13. Emanuel L and Scandrett KG (2010) Decisions at the end of life: have we come of age? BMC Medicine 857 https://doi.org/10.1186/17417015-8-57 PMID: 20932275 PMCID: 2964548

14. Fried TR, Bullock K, and lannone L, et al., (2009) Understanding advance care planning as a process of health behavior change $J$ Am Geriatr Soc 57(9) 1547-1555 https://doi.org/10.1111/j.1532-5415.2009.02396.x PMID: 19682120 PMCID: 2783892

15. Kurella Tamura M, and Cohen LM (2010) Should there be an expanded role for palliative care in end-stage renal disease? Curr Opin Nephrol Hypertens 9(6) 556-560 https://doi.org/10.1097/MNH.0b013e32833d67bc

16. Kaasa S, Loge JH, and Aspro M, et al. (2018) Integration of oncology and palliative care: a Lancet Oncology Commission Lancet Oncol 19(11) e588-e653 https://doi.org/10.1016/S1470-2045(18)30415-7 PMID: 30344075 
17. Mack JW, Cronin A, and Keating NL, et al. (2012) Associations between end-of-life discussion characteristics and care received near death: a prospective cohort study J Clin Oncol 30 4387-4395 https://doi.org/10.1200/JCO.2012.43.6055 PMID: 23150700 PMCID: 3675701

18. Sborov K, Giaretta S, and Koong A, et al. (2019) Impact of accuracy of survival predictions on quality of end-of-life care among patients with metastatic cancer who receive radiation therapy J Oncol Pract 15(3) e262-e270 https://doi.org/10.1200/JOP.18.00516 PMID: 30620629

19. Hagerty RG, Butow PN, and Ellis PM, et al. (2005) Communicating with realism and hope: incurable cancer patients' views on the disclosure of prognosis J Clin Oncol 23 1278-1288 https://doi.org/10.1200/JCO.2005.11.138 PMID: 15718326

20. Pardon K, Deschepper R, and Vander Stichele R, et al. (2011) Are patient's preferences for information and participation in medical decision-making being met? Interview study with lung cancer patients Palliat med 25 62-70 https://doi.org/10.1177/0269216310373169

21. Wright AA, Zhang B, and Ray A, et al. (2008) Associations between end-of-life discussions, patient mental health, medical care near death, and caregiver bereavement adjustment JAMA 300 1665-1673 https://doi.org/10.1001/jama.300.14.1665 PMID: 18840840 PMCID: 2853806

22. Hanson LC, Danis M, and Garrett J (1997) What is wrong with end-of-life care? Opinions of bereaved family members J Am Geriatr Soc 45 1339-1344 https://doi.org/10.1111/j.1532-5415.1997.tb02933.x PMID: 9361659

23. Keating NL, Landrum MB, and Rogers SO Jr, et al. (2010) Physician factors associated with discussions about end-of-life care Cancer 116(4) 998-1006 https://doi.org/10.1002/cncr.24761 PMID: 20066693 PMCID: 2819541

24. Sahm S, Will R, and Hommel G (2005) What are cancer patients' preferences about treatment at the end of life, and who should start talking about it? A comparison with healthy people and medical staff Supp Care Cancer 13(4) 206-214 https://doi.org/10.1007/ s00520-004-0725-z

25. John E, Heffner JE, and Barbieri C (2000) End-of-life care preferences of patients enrolled in cardiovascular rehabilitation programs Chest [updated May 28, 2015] 117(5) 1474-1479 https://doi.org/10.1378/chest.117.5.1474

26. Mack JW, Cronin A, and Taback N, et al. (2012) End-of-life care discussions among patients with advanced cancer: a cohort study Ann Intern Med 156(3) 204-210 https://doi.org/10.7326/0003-4819-156-3-201202070-00008 PMID: 22312140 PMCID: 3616320

27. Schneiter MK, Karlekar MB, and Crispens MA (2018) The earlier the better: the role of palliative care consultation on aggressive end of life care, hospice utilization, and advance care planning documentation among gynecologic oncology patients Support Care Cancer 27(5) 1927-1934 https://doi.org/10.1007/s00520-018-4457-x PMID: 30209601

28. Johnson SB, Butow PN, and Bell ML (2018) A randomised controlled trial of an advance care planning intervention for patients with incurable cancer BrJ Cancer 119(10) 1182-1190 https://doi.org/10.1038/s41416-018-0303-7 PMID: 30369600 PMCID: 6251033

29. Biola H, Sloane PD, and Williams CS, et al. (2010) Preferences versus practice: life-sustaining treatments in last months of life in longterm care J Am Med Dir Assoc 11(1) 42-51 https://doi.org/10.1016/j.jamda.2009.07.005 PMID: 20129214 PMCID: 3692740

30. Hillman K (2010) Dying safely Int J Qual Health Care 22(5) 339-340 https://doi.org/10.1093/intqhc/mzq045 PMID: 20709706

31. Wright AA, Keating NL, and Balboni TA, et al. (2010) Place of death: correlations with quality of life of patients with cancer and predictors of bereaved caregivers' mental health J Clin Oncol 28(29) 4457-4464 https://doi.org/10.1200/JCO.2009.26.3863 PMID: 20837950 PMCID: 2988637

32. O'Connor AE, Winch S, and Lukin W, et al. (2011) Emergency medicine and futile care: taking the road less travelled Emerg Med Australas 23(5) 640-643 https://doi.org/10.1111/j.1742-6723.2011.01435.x

33. Miles SH (1987) Advanced directives to limit treatment: the need for portability J Am Geriatr Soc 35(1) 74-76 https://doi. org/10.1111/j.1532-5415.1987.tb01323.x PMID: 3794150

34. Bomba PA, Kemp M, and Black JS (2012) POLST: an improvement over traditional advance directives Cleve Clin J Med 79(7) 457-464 https://doi.org/10.3949/ccjm.79a.11098 PMID: 22751627 
35. Lamas D, Panariello N, and Henrich N, et al. (2018) Advance care planning documentation in electronic health records: current challenges and recommendations for change J Palliative Med 21(4) 522-528 https://doi.org/10.1089/jpm.2017.0451

36. Paladino J, Bernacki R, and Neville BA, et al. (2019) Evaluating an intervention to improve communication between oncology clinicians and patients with life-limiting cancer: a cluster randomized clinical trial of the serious illness care program JAMA Oncol 5(6) 801-809 https://doi.org/10.1001/jamaoncol.2019.0292 PMID: 30870556

37. Hirvonen OM, Alalahti JE, and Syrjanen KJ, et al. (2018) End-of-life decisions guiding the palliative care of cancer patients visiting emergency department in South Western Finland: a retrospective cohort study BMC Palliat Care 17(1) 128 https://doi.org/10.1186/ s12904-018-0383-4 PMID: 30558583 PMCID: 6297980

38. Kass-Bartelmes BL and Hughes R (2004) Advance care planning: preferences for care at the end of life J Pain Palliat Care Pharmacother 18(1) 87-109 PMID: 15148012

39. Yennurajalingam S, Rodrigues LF, and Shamieh OM, et al. (2018) Decisional control preferences among patients with advanced cancer: an international multicenter cross-sectional survey Palliat Med 32(4) 870-880 https://doi.org/10.1177/02692163177474442

40. Rao JK, Anderson LA, and Lin F, et al. (2014) Completion of advance directives among U.S. consumers Am J Prev Med 46(1) 65-70 https://doi.org/10.1016/j.amepre.2013.09.008

41. Mack JW, Walling A, and Dy S, et al. (2015) Patient beliefs that chemotherapy may be curative and care received at the end of life among patients with metastatic lung and colorectal cancer Cancer 121(11) 1891-1897 https://doi.org/10.1002/cncr.29250 PMID: 25677655 PMCID: 4441582

42. Happ MB, Capezuti E, and Strumpf NE, et al. (2002) Advance care planning and end-of-life care for hospitalized nursing residents J Am Geriatr Soc [updated May 28, 2015; cited November 04, 2014] 50(5) 829-837 https://doi.org/10.1046/j.1532-5415.2002.50207.x PMID: 12028168

43. Lin CP, Evans CJ, and Koffman J, et al. (2019) The conceptual models and mechanisms of action that underpin advance care planning for cancer patients: a systematic review of randomized controlled trials Palliat Med 33(1) 5-23 https://doi. org/10.1177/0269216318809582

44. Hagerty RG, Butow PN, and Ellis PM, et al. (2004) Cancer patient preferences for communication of prognosis in the metastatic setting J Clin Oncol 22 1721-1730 https://doi.org/10.1200/JCO.2004.04.095 PMID: 15117995

45. Fallowfield $L$, Jenkins VA, and Beveridge HA (2002) Truth may hurt but deceit hurts more: communication in palliative care Palliat Med 16 297-303 https://doi.org/10.1191/0269216302pm575oa PMID: 12132542

46. Temel JS, Shaw AT, and Greer JA (2016) Challenge of prognostic uncertainty in the modern era of cancer therapeutics J Clin Oncol 34(30) 3605-3608 https://doi.org/10.1200/JCO.2016.67.8573 PMID: 27551112

47. Teno J, Lynn J, amd Wenger N, et al. (1997) Advance directives for seriously ill hospitalized patients: effectiveness with the patient self-determination act and the SUPPORT intervention-SUPPORT Investigators. Study to prognoses and preferences for outcomes and risks of treatments (SUPPORT). The SUPPORT principals investigators J Am Geriatric Sock 45 500-507 https://doi. org/10.1111/j.1532-5415.1997.tb05178.x

48. Parsons HA, de la Cruz MJ, and Zhukovsky DS, et al. (2010) Characteristics of patients who refuse do-not-resuscitate orders upon admission to an acute palliative care unit in a comprehensive cancer center Cancer 116(12) 3061-3070 https://doi.org/10.1002/ cncr.25045 PMID: 20564412

49. Levin TT, Li Y, and Weiner JS, et al. (2008) How do-not-resuscitate orders are utilized in cancer patients: timing relative to death and communication-training implications Palliat and Supp Care 6 341-348 https://doi.org/10.1017/S1478951508000540

50. Costantini M, Beccaro M, and Higginson IJ (2008) Cancer trajectories at the end of life: is there an effect of age and gender? BMC Cancer 8127 https://doi.org/10.1186/1471-2407-8-127 PMID: 18454854 PMCID: 2386793

51. Kolva E, Rosenfeld B, and Saracino R (2018) Assessing the decision-making capacity of terminally ill patients with cancer Am J Geriatr Psychiatry 26(5) 523-531 https://doi.org/10.1016/j.jagp.2017.11.012 PMID: 29398351 PMCID: 6345171 
52. Conors AF, Dawson NV, and Desbiens NA, et al. (1995) A controlled trial to improve care for seriously ill hospitalized patients. The study to understand prognoses and preferences for outcomes and risks of treatments (SUPPORT). The SUPPORT Principal Investigators JAMA 274 1591-1598 https://doi.org/10.1001/jama.1995.03530200027032

53. Morrell ED, Brown BP, and Qi R, et al. (2008) The do-not-resuscitate order: associations with advance directives, physician specialty and documentation of discussion 15 years after the Patient Self Determination Act J Med Ethics 34 642-647 https://doi.org/10.1136/ jme.2007.022517 PMID: 18757631

54. Quil TE (2000) Perspectives on care at the close of life: initiating end-of-life discussions with seriously ill patients: addressing the "elephant in the room" JAMA 284 2502-2507 https://doi.org/10.1001/jama.284.19.2502

55. Ermers DJ, van Bussel KJ, and Perry M, et al. (2018) Advance care planning for patients with cancer in the palliative phase in Dutch general practices Fam Pract 36(5) 1-7

56. Schickedanz AD, Schillinger D, and Landefeld CS, et al. (2009) A clinical framework for improving the advance care planning process:start with patients self-identified barriers J Am Geriatr Soc 57 31-39 https://doi.org/10.1111/j.1532-5415.2008.02093.x PMID: 19170789 PMCID: 2788611

57. Wallace CL (2015) Family communication and decision making at the end of life: a literature review Palliat Support Care 13 815-825 https://doi.org/10.1017/S1478951514000388

58. Hobbs GS, Landrum MB, and Arora NK, et al. (2015) The role of families in decisions regarding cancer treatments Cancer $13815-825$

59. Narang AK, Wright AA, and Nicholas LH (2015) Trends in advance care planning in patients with cancer: results from a national longitudinal survey JAMA Oncol 1(5) 601-618 https://doi.org/10.1001/jamaoncol.2015.1976 PMID: 26181909 PMCID: 4537325

60. Sulmasy DP, Sood JR, and Ury WA (2004) The quality of care plans for patients with do-not-resuscitate orders Arch Intern Med 164 1573-1578 https://doi.org/10.1001/archinte.164.14.1573 PMID: 15277292

61. Ying G, Palmer JL, and Bianty J, et al. (2010) Advance directives and do-not-resuscitate orders in patients with cancer with metastatic spinal cord compression: advanced care planning implications J Palliat Med 13 513-517 https://doi.org/10.1089/jpm.2009.0376

62. Weiner JS and Roth J (2006) Avoiding iatrogenic harm to patient and family while discussing goals of care near end of life J Palliat Med 9 451-463 https://doi.org/10.1089/jpm.2006.9.451 PMID: 16629574

63. Dionne-Odom JN, Azuero A, and Lyons KD, et al. (2015) Benefits of early versus delayed palliative care to informal family caregivers of patients with advanced cancer: outcomes from the ENABLE III randomized controlled trial J Clin Oncol 33 1446-1452 https://doi. org/10.1200/JCO.2014.58.7824 PMID: 25800762 PMCID: 4404423

64. Barry LC, Kasl SV, and Prigerson HG (2002) Psychiatric disorders among bereaved persons: the role of perceived circumstances of death and preparedness for death Am J Geriatr Psychiatry 10 447-457 https://doi.org/10.1097/00019442-200207000-00011 PMID: 12095904

65. Kurita K, Lachs MS, and Adelman RD, et al. (2018) Mild cognitive dysfunction of caregivers and its association with care recipients' end-of-life plans and preferences PLoS ONE 13(4) e0196147 https://doi.org/10.1371/journal.pone.0196147 PMCID: 5927428

66. Later EB and King D (2007) Advance directives: results of a community education symposium Crit Care Nurse 27(6) 31-5 PMID: 18032684

67. Lamont EB and Siegler M (2000) Paradoxes in cancer patients' advance care planning J Palliat Med 3(1) 27-35 https://doi.org/10.1089/ jpm.2000.3.27

68. Azoulay E, Pochard F, and Kentish-Barnes N, et al. (2005) Risk of posttraumatic stress symptoms in family members of intensive care unit patients Am J Respir CritCare Med 171 987-994 https://doi.org/10.1164/rccm.200409-12950C

69. Dy SM (2006) Enteral and parenteral nutrition in terminally ill cancer patients: a review of the literature Am J Hosp Palliat Care 23(5) 369 https://doi.org/10.1177/1049909106292167 PMID: 17060304

70. Bruera E, Hui D, and Dalal S, et al. (2013) Parenteral hydration in patients with advanced cancer: a multicenter, double-blind, placebocontrolled randomized trial J Clin Oncol 31(1) 111 https://doi.org/10.1200/JCO.2012.44.6518 PMCID: 3530688 
71. Reisfield GM, Wallace SK, and Munsell MF, et al. (2006) Survival in cancer patients undergoing in-hospital cardiopulmonary resuscitation: a meta-analysis Resuscitation 71 152-160 https://doi.org/10.1016/j.resuscitation.2006.02.022 PMID: 16987581

72. Bruckel JT, Wong SL, and Chan PS, et al. (2017) Patterns of resuscitation care and survival after in-hospital cardiac arrest in patients with advanced cancer J Oncol 13(10) e821-e830

73. Preston NJ, Hurlow A, and Brine J, et al. (2012) Blood transfusions for anaemia in patients with advanced cancer Cochrane Database Syst Rev 15(2) CD009007

74. Goksu SS, Gunduz S, and Unal D, et al. (2014) Use of blood transfusion at the end of life: does it have any effects on survival of cancer patients? Asian Pacific J Cancer Prevent 15(10) 4251-4254 https://doi.org/10.7314/APJCP.2014.15.10.4251

75. McClain K and Perkins $\mathrm{P}$ (2002) Terminally ill patients in the emergency department: a practical overview of end-of-life issues Emerg Nurs J 28(6) 515-522 https://doi.org/10.1067/men.2002.129825

76. National Audit Office (2008) End of Life Care: Report by the Comptroller and Auditor General, London, UK

77. NSW Health (2011) Advance Planning for Quality Care at End of Life (Australia: Department of Health, NSW)

78. Le BH and Watt JN (2010) Care of the dying in Australia's busiest hospital: benefits of palliative care consultation and methods to enhance access J Palliat Med 13(7) 855-860 https://doi.org/10.1089/jpm.2009.0339 PMID: 20636157

79. Byrne M, Tresgallo M, and Saroyan J, et al. (2011) Qualitative analysis of consults by a pediatric advanced care team during its first year of service American J Hosp Palliat Med 28(2) 109-117 https://doi.org/10.1177/1049909110376626

80. Paterson BC, Duncan R, and Conway R, et al. (2009) Introduction of the liverpool care pathway for end of life care to emergency medicine Emerg Med J 26(11) 777-779 https://doi.org/10.1136/emj.2008.067249 PMID: 19850797

81. Connors AF, Dawson NV, and Desbiens NA, et al. (1995) A controlled trial to improve care for seriously ill hospitalized patients JAMA 274(20) 1591-1598 https://doi.org/10.1001/jama.1995.03530200027032

82. Reason J (1990) The contribution of latent human failures to the breakdown of complex systems Philos Trans R Soc Lond B Biol Sci 327(1241) 475-484 https://doi.org/10.1098/rstb.1990.0090 PMID: 1970893 